\title{
Effect of Green Tea Consumption on Selected Metabolic Biomarkers in Asian Indian Women with Metabolic Syndrome
}

\author{
Kasturi Sen Ray*, Pooja R. Singhania \\ Department of Food Science and Nutrition, Post Graduate Studies and Research in Home Science, S.N.D.T. \\ Women's University, Mumbai, India \\ Email: kasturisenray@gmail.com
}

Received 14 September 2014; revised 10 October 2014; accepted 3 November 2014

Copyright (C) 2014 by authors and Scientific Research Publishing Inc.

This work is licensed under the Creative Commons Attribution International License (CC BY). http://creativecommons.org/licenses/by/4.0/

(c) (i) Open Access

\begin{abstract}
Evidence for benefits of anti-oxidative power of polyphenols in cardiovascular diseases has been established. In the present study, effect of polyphenol rich green tea on selected metabolic biomarkers among Asian Indian women with metabolic syndrome in normal free living condition has been recorded. Thirty three Asian Indian women ( $>30$ y) confirmed as having metabolic syndrome, were enrolled for the present study based on written informed consent. Subjects were asked to consume three cups of green tea daily for a period of four months. Regular telephonic contact and periodic visit to supply the tea were made to ensure compliance with the intervention and maintenance of lifestyle and dietary pattern, as followed before the experimental period. Parameters analyzed at baseline have been used as control data to eliminate individual variation. Doubleblind analysis of selected metabolic markers was done at baseline, 2 months and 4 months of the intervention period. At four months, a significant reduction from baseline was observed in weight $(2 \%)$, waist circumference $(4.5 \%)$, blood sugar $(4 \%)$, glycosylated hemoglobin $(4 \%)$, total cholesterol $(11 \%)$ and LDL cholesterol $(13 \%)(p<0.01)$. The effect of green tea consumption on BMI, fasting insulin, HDL cholesterol, triglyceride, VLDL, C-reactive protein and homocysteine levels was either inconsistent or non significant. The present study showed that green tea consumption by free living subjects with metabolic syndrome resulted in significant improvements in some of the cardiovascular risk factors including visceral fat, blood sugar and cholesterol level.
\end{abstract}

\section{Keywords}

Green Tea, Metabolic Syndrome, Metabolic Biomarkers, Asian Indian Women

\footnotetext{
${ }^{*}$ Corresponding author.
}

How to cite this paper: Ray, K.S. and Singhania, P.R. (2014) Effect of Green Tea Consumption on Selected Metabolic Biomarkers in Asian Indian Women with Metabolic Syndrome. Food and Nutrition Sciences, 5, 2167-2176. 


\section{Introduction}

There is strong evidence to suggest beneficial effects of dietary polyphenols in reducing several oxidative stress related health problems including cardiovascular mortality rate [1]. Catechins, a group of polyphenols, present in green tea, have been found to exhibit anti-oxidant properties. Studies have reported that regular consumption of green tea may improve lipid profile by inhibiting key enzymes involved in lipid biosynthesis, reducing intestinal lipid absorption, regulate vascular tone, prevent progression of atherosclerosis by preventing vascular inflammation and inhibit thrombogenesis [2]. Anti-obesity effects of green tea catechins in terms of increased energy expenditure, increased fat oxidation, decreased appetite, and decreased GI absorption have been reported by Rains, Agarwal \& Maki (2011) [3]. Folic acid and caffeine present in green tea may have an added advantage of lowering homocysteine level [4] [5] and CRP levels [6].

Metabolic syndrome (MS) is characterized by presence of several risk factors such as diabetes and prediabetes, abdominal obesity, high cholesterol and high blood pressure [7]. These parameters may be positively affected by supplementation with green tea polyphenols. Ikeda (2008) [8] suggested that tea catechins and also the heat-treated tea catechins may contribute to prevention of metabolic syndrome. Recent studies have suggested that green tea may be incorporated into a targeted dietary program as part of public health policy to improve cardiovascular health [9]. It is important to establish role of regular green tea consumption on different metabolic biomarkers. The present study aims to determine the effect of green tea supplementation on metabolic biomarkers among the metabolic syndrome patients.

\section{Experimental Methods}

Based on the Modified NCEP ATP III definitions for metabolic syndrome among Asians [10], a large number of urban female subjects leading sedentary life style were screened. The present study is a part of larger study wherein subjects with metabolic syndrome were randomly assigned to green tea and black tea group. Thirty three female subjects in the age group of 30 - 75 y confirmed as having metabolic syndrome were enrolled for the Green tea intervention. The free living volunteers were asked not to deviate or to maintain the same lifestyle and dietary pattern as followed before the experimental period. A regular telephonic contact and periodic visit to supply the tea was made to ensure compliance with intervention. Written informed consent was obtained from all the subjects.

Anthropometric measurements such as weight and waist circumference were taken as per standard protocol. The proposal was approved by the Institutional Ethics committee of Department of Pharmacology, Grant medical College and Sir J.J. Group of Hospitals, Mumbai, India.

\subsection{Intervention}

Subjects were asked to consume three cups of green tea daily for a period of four months. Zaveri (2006) [11], reported that one cup of green tea may contain 100 - $200 \mathrm{mg}$ of Epigallocatechin gallate (EGCG). This is much higher in comparison to the levels in the Indian sample analyzed (68.67 mg/cup). 3 - 4 cups of tea/day (450 $600 \mathrm{ml} /$ day) would provide 155 - $206 \mathrm{mg}$ of EGCG and about $434.5 \mathrm{mg}$ of total catechins (Table 1).

\begin{tabular}{ccc} 
Table 1. Polyphenol composition of green tea brew. & \\
\hline & Catechin & 16.2 \\
Catechin $(\mathrm{mg} / \mathrm{L})$ & EC & 65.5 \\
& ECG & 82.8 \\
& EGCG & 343.8 \\
Galactocatechin $(\mathrm{mg} / \mathrm{L})$ & EGC & 187.9 \\
& GC & 27.9 \\
Total Poly phenols (mg/L) & Folin & 1020 \\
Ratio & T.Catechin/T.Phenolics & 0.7 \\
Caffeine (mg/L) & & 193.5 \\
TSS (mg/L) & & 2.8
\end{tabular}

EC—Epicatechin, ECG—Epicatechin gallate, EGCG—Epigalacto catechins gallate, EGC—Epigallacto catechins, EGC—Epigallacto catechins, GC—Gallacto catechins. 
Green tea bags of standardized weight and concentration (Table 1) from the same batch were supplied to all participants every fortnight. The method for preparation of green tea was carefully explained and demonstrated in groups at the beginning of the study. Subjects were allowed to add honey or sugar to the tea based on personal preference. They were specifically advised to refrain from modifying other lifestyle factors such as diet and physical activity during the intervention period. Frequent follow-up and monitoring was done to ensure that the subjects adhered to the experimental protocol.

\subsection{Blood Sampling}

$5 \mathrm{ml}$ of peripheral venous blood was collected by vein puncture using a dry, disposable syringe by trained pathologists from local blood collection centre between 8 am - 9 am after an overnight fast (10.5 - 12 hours). Blood was collected in sterile tubes containing EDTA as anticoagulant for plasma separation. For serum separation, blood was collected without EDTA. Plasma and serum were separated by centrifugation at 3000 rpm for 15 min, stored at $4^{\circ} \mathrm{C}$ and send to central pathological lab where samples from different localities were analyzed for various biochemical assays.

\subsection{Biochemical-Analytical Methods}

Fasting blood samples were analyzed for glucose (GOD-POD method) [12], insulin (Radio immune assay) [13], glycosylated hemoglobin (colometirc method) [14], total cholesterol (CHOD-PAP with ATCS method) [12] [15]-[17], triglyceride (GPO-POD method with ESPAS) [18]-[21], HDL-cholesterol [22]-[27], LDL-cholesterol (empirical equation of Friedewald et al. 1972) [28]. Inflammatory biomarkers such as C-Reactive Protein (CRP Turbilatex with high sensitivity and specificity was used) [29]-[34] and Homocysteine (Hcy) using Automated Enzymatic Assay for Homocysteine [35] were also analyzed.

The anthropometric and biochemical parameters such as weight, waist circumference, BMI, blood sugar, fasting insulin, glycosylated hemoglobin, lipid profile, C-reactive protein and homocysteine levels were recorded at baseline, 2 months and 4 months.

\subsection{Statistical Analysis}

Numerical data are presented as mean values \pm S.D. Mean differences in the metabolic markers from baseline to 2 months and 4 months and from 2 months to 4 months were compared using student t test. All analysis was done using Statistical Package for Social Sciences (SPSS) version 12.0.

\section{Results}

Regular consumption of 3 cups of green tea per day by the subjects resulted in significant differences in the MS biomarkers. The anthropometric and biochemical parameters were tested at baseline, 2 months and then at 4 months.

A significant reduction in weight of $2 \%$ was observed from baseline to 4 months $(p<0.05)$. At 2 months, the reduction was highly significant which showed the immediate effects of green tea on weight. BMI also showed a significant decline in the first 2 months of intervention (Table 2). Waist circumference reduced by $4.5 \%$ at 4 months as compared to baseline $(p<0.01)$ which indicates the impact of green tea on visceral fat.

At the end of 4 months, fasting blood sugar levels decreased by $4 \%$ from baseline $(p<0.01)$. HbA1c, which is indicative of long term blood sugar control, also showed a highly significant reduction after 4 months of green tea consumption ( $<$ 0.01). But fasting insulin level of MS subjects fluctuated within the normal range (Table 3).

After 4 months of green tea consumption, total cholesterol and the LDL cholesterol levels reduced significantly by $11 \%$ and $13 \%$ respectively from baseline $(p<0.01)$ whereas HDL cholesterol levels showed a non significant decrease. Green tea supplementation in female with MS showed an inconsistent effect on Triglyceride level (Figure 1). In fact, a significant rise was seen in the first 2 months $(\mathrm{p}<0.05)$ which is not a favorable effect. As VLDL contains large amount of TG, the effect of supplementation followed similar effect for VLDL.

The anti-oxidative power of green tea polyphenols may have positive impact on two important inflammatory biomarkers; CRP and HCY, which have been analyzed in the present study. Study results showed an increasing trend for both CRP and Hcy at 4 months period. CRP levels were much higher than normal at baseline and increased significantly by the end of intervention period. HCY levels in female subjects with MS showed a non significant decrease in the first 2 months of consuming green tea but increased on continued supplementation (Table 4). 


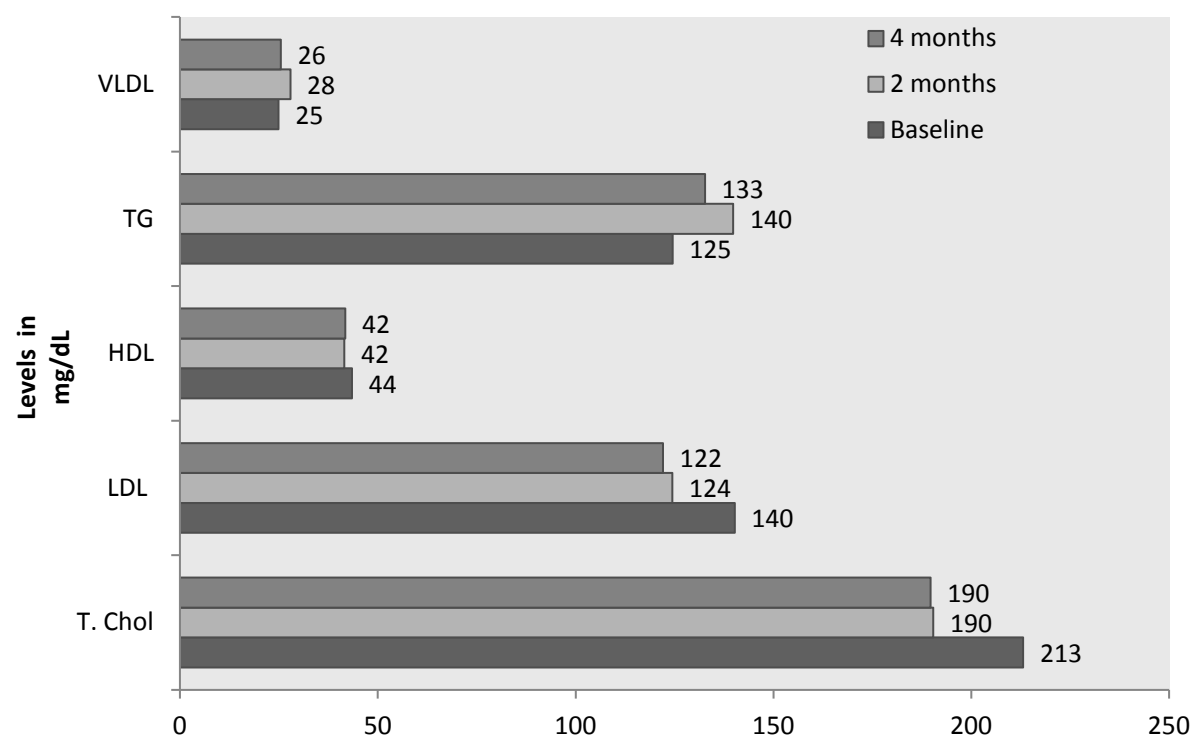

Figure 1. Effect of Green tea on lipid profile of MS subjects $(n=33)$.

Table 2. Effect of Green tea on weight and waist circumference of MS subjects ( $\mathrm{n}=33$ ).

\begin{tabular}{cccccccccc}
\hline Subject & $\begin{array}{c}\text { Base } \\
\text { Mean }\end{array}$ & $\begin{array}{c}\text { Base } \\
\text { SD }\end{array}$ & $\begin{array}{c}\mathbf{2} \mathbf{~ m o} \\
\text { Mean }\end{array}$ & $\begin{array}{c}\mathbf{2} \mathbf{~ m o} \\
\text { SD }\end{array}$ & $\begin{array}{c}\mathbf{4} \mathbf{~ m o} \\
\text { Mean }\end{array}$ & $\begin{array}{c}\mathbf{4} \mathbf{~ m o} \\
\text { SD }\end{array}$ & $\begin{array}{c}\text { SL } \\
\mathbf{0 - 2 m}\end{array}$ & $\begin{array}{c}\text { SL } \\
\Delta_{\mathbf{2}-\mathbf{m}}\end{array}$ & $\begin{array}{c}\text { SL } \\
\Delta_{\mathbf{0}-\mathbf{m}}\end{array}$ \\
\hline Wt. & 73.7 & 13.1 & 72.8 & 13.2 & 72.2 & 13.3 & $* *$ & NS & $*$ \\
BMI & 29.7 & 5.1 & 29.4 & 5.2 & 29.5 & 5.2 & $* *$ & NS & NS \\
WC & 102.7 & 11.2 & 99.6 & 10.9 & 98.2 & 10.8 & $*$ & NS & $* *$ \\
\hline
\end{tabular}

Wt. — weight, BMI—Body Mass Index, WC—Waist circumference, Base—Baseline, mo—month, SL—significance level, NS— non significant, ${ }^{*} \mathrm{p}<0.05, \stackrel{*}{\mathrm{p}}<0.01$.

Table 3. Effect of Green tea on blood sugars and insulin of MS subjects $(n=33)$.

\begin{tabular}{cccccccccc}
\hline Subject & Base & Base & $\mathbf{2}$ mo & $\mathbf{2 ~ m o}$ & $\mathbf{4}$ mo & $\mathbf{4 ~ m o}$ & SL & SL & SL \\
& Mean & SD & Mean & SD & Mean & SD & $\Delta_{\mathbf{0}-\mathbf{2 m}}$ & $\Delta_{\mathbf{2}-4 \mathbf{m}}$ & $\Delta_{\mathbf{0}-4 \mathbf{m}}$ \\
\hline FBS & 84.9 & 11.2 & 82.7 & 11.2 & 81.5 & 13.4 & NS & NS & ${ }^{* *}$ \\
HbA1c & 6.04 & 0.5 & 5.9 & 0.5 & 5.8 & 0.7 & $*$ & NS & $* *$ \\
F.Ins & 11.7 & 6.8 & 13.6 & 8.9 & 11.4 & 4.7 & NS & NS & NS \\
\hline
\end{tabular}

FBS—Fasting blood sugar, HbA1c—glycosylated hemoglobin, F.Ins—Fasting insulin, Base—Baseline, mo—month; SLsignificance level, NS—non significant, ${ }^{\mathrm{p}}<0.05, \stackrel{* *}{\mathrm{p}}<0.01$.

Table 4. Effect of Green tea on inflammatory biomarkers of MS subjects $(\mathrm{n}=33)$.

\begin{tabular}{cccccccccc}
\hline Subject & $\begin{array}{c}\text { Base } \\
\text { Mean }\end{array}$ & $\begin{array}{c}\text { Base } \\
\text { SD }\end{array}$ & $\begin{array}{c}\mathbf{2} \text { mo } \\
\text { Mean }\end{array}$ & $\begin{array}{c}\mathbf{2} \text { mo } \\
\text { SD }\end{array}$ & $\begin{array}{c}\mathbf{4} \text { mo } \\
\text { Mean }\end{array}$ & $\begin{array}{c}\mathbf{4} \text { mo } \\
\text { SD }\end{array}$ & $\begin{array}{c}\text { SL } \\
\text {-2m }\end{array}$ & $\begin{array}{c}\text { SL } \\
\Delta_{2-4 m}\end{array}$ & $\begin{array}{c}\text { SL } \\
\Delta_{\mathbf{0}-4 m}\end{array}$ \\
\hline CRP & 5.3 & 5.0 & 6.7 & 5.6 & 7.9 & 7.0 & NS & NS & $*$ \\
HCY & 16.3 & 9.3 & 14.6 & 5.7 & 18.9 & 7.6 & NS & $* *$ & NS \\
\hline
\end{tabular}

CRP—C-reactive protein, HCY—Homocysteine, Base—Baseline, mo—month; SL—significance level, NS—non significant, ${ }^{*} \mathrm{p}<0.05$, $\mathrm{p}<0.01$.

\section{Discussion}

\subsection{Weight Status}

\subsubsection{Weight}

Reduction in weight observed within 4 months of consuming green tea without introducing any other lifestyle 
changes in Asian women with metabolic syndrome (Table 2) strengthens the evidence for weight loss attributed to green tea anti-oxidants. Wolfram et al. (2006) [36] suggested that green tea may stimulate body metabolism thereby contributing to anti-obesity effects. Green tea extract has thermogenic effect which increases energy expenditure and promotes fat oxidation in the body thereby playing a role in controlling body composition [37].

\subsubsection{Waist Circumference}

Waist circumference, indicative of visceral fat, also showed highly significant reduction by the end of 4 months (Table 2). Decrease in visceral fat is more important as far as metabolic disorders are concerned since it has been recognized as a major risk for obesity-related diseases contributing to pro-oxidant and pro-inflammatory states as well as to alterations in glucose and lipid metabolisms [38] [39]. A recent study on elderly subjects with MS showed that consumption of $1.0 \mathrm{~g}$ of green tea three times a day for 2 months was effective in inducing weight loss, reducing BMI and waist circumference [40].

\subsubsection{Body Mass Index}

While weight and waist circumference showed a significant decline within 4 months, but BMI did not show any significant changes (Table 2). Studies have shown that BMI serves as a relative measure of body weight but is a poor indicator of body composition in terms of percent body fat [41] [42].

\subsection{Blood Glucose}

\subsubsection{Fasting Blood Sugar}

A highly significant reduction in fasting blood sugar levels $(\mathrm{p}<0.01)$ was observed in the female subjects upon consuming green tea for 4 months (Table 3). At 2 months, overall trend of reduction was observed but not at significant level. Maruyama et al. (2009) [43] showed that Japanese men who consumed green tea at 3\% concentration showed lower mean values of fasting blood glucose than those who consumed $1 \%$ concentration showing that at a high concentration, green tea has the potential to reduce blood glucose levels.

\subsubsection{Glycosylated Hemoglobin (HbA1c)}

HbA1c levels decreased significantly to below 6\% from baseline to 4 months (Table 3). In non-diabetics, HbA1c can be considered as a surrogate marker for metabolic syndrome [44] and in individuals with type 2 diabetes; higher HbA1c levels have been associated with increased risk of coronary heart disease, cardiovascular disease and total mortality [45]. A recent meta-analysis of 17 randomized controlled trials revealed that green tea consumption decreased fasting glucose and HbA1c concentrations and significant reduction in fasting insulin levels were observed upon subgroup analyses [46].

\subsubsection{Fasting Insulin}

Fasting insulin levels showed an increase in the first 2 months of intervention and then returned back to baseline by the end of 4 months (Table 3). The range for normal fasting insulin is very wide (2 - $25 \mu \mathrm{IU} / \mathrm{mL}$ ) making it difficult to predict disease risk, especially with insulin resistant or insulin deficient diabetic condition [47]. The phenolic compounds in tea are proposed to stimulate pancreatic $\beta$ cells causing an elevation in insulin response which attenuates postprandial glycemia [48].

\subsection{Lipid Levels}

\subsubsection{Total and LDL Cholesterol}

Total cholesterol and LDL cholesterol (derived from total cholesterol) levels reduced significantly ( $p<0.01)$ and at 4 months they were within the normal range ( $<200 \mathrm{mg} / \mathrm{dL})$ [49] (Figure 1). This indicates rich supply of antioxidants through tea protecting against oxidative stress and thereby atherosclerosis. Results from animal studies suggest that polyphenols in green tea may block cholesterol from being absorbed in the intestine and also help the body get rid of cholesterol [50]. Chan et al. (1999) [51] proposed that gallate esters in catechins interfere with biliary micelle system in the lumen of the intestine by forming insoluble co-precipitates of cholesterol and increasing the fecal excretion of cholesterol.

Meta-analysis of 14 randomized controlled trials by Zhen et al. (2011) [9] showed that consumption of green tea beverages and green tea extract significantly lowered total cholesterol by $7.2 \mathrm{mg} / \mathrm{dL}(\mathrm{p}<0.001)$ and LDLcholesterol by $2.19 \mathrm{mg} / \mathrm{dL}(\mathrm{p}<0.001)$. However, the mean change in blood HDL-cholesterol concentration was 
not significant.

\subsubsection{HDL Cholesterol}

High HDL independently exerts a beneficial effect on lowering cardiovascular disease risk [52]. In the present study, HDL levels decreased with green tea consumption (Figure 1) which is not a favorable action. In a study on 13,916 Japanese workers aged 40 - 69 years, green tea consumption was not significantly associated with serum triglycerides and HDL cholesterol [53].

\subsubsection{Triglyceride \& VLDL Cholesterol}

Triglyceride level and VLDL cholesterol levels showed an initial rise at 2 months and then started going down by 4 months but were still higher than baseline levels (Figure 1). Juhel et al. (2000) [54] evaluated the inhibitory activity of green tea extract (AR25 standardized at 25\% catechins) on gastric and pancreatic lipase activities in- vitro using triolein, a long-chain triglyceride as substrate. The green tea extract AR25 exhibited marked inhibition of digestive lipases in vitro which is likely to reduce lipolysis of triglycerides and fat digestion in humans. This may provide a possible explanation of initial rise in serum triglycerides.

\subsection{Inflammatory Biomarkers}

\subsubsection{C-Reactive Protein (CRP) Levels}

Initially considered as a marker of inflammation, a marginally high CRP value (2.4 mg/l) in healthy asymptomatic people may cause two times higher future risk of a coronary event than those with levels $<1.0 \mathrm{mg} / \mathrm{l}$ [55]. Hs-CRP and total cholesterol: HDL ratio, have been found to be the only plasma markers that independently predict cardiovascular disease risk in healthy women [56].

CRP levels among Asian Indian women with metabolic syndrome showed a steady rise with green tea supplementation despite the rich supply of anti-oxidants. This observation needs in depth study, especially in context to MS population. Theoretically, the polyphenols in green tea is expected to help in reduction of the markers of inflammation but the study results are contradictory (Table 4). Maki et al. (2010) [57] examined the relationship between green tea consumption and serum concentrations of CRP in a large population of free-living Japanese men and women. They observed that green tea consumption showed no measurable relationship with CRP concentrations in either men or women.

\subsubsection{Homocysteine (HCY)}

Homocysteine levels also showed inconsistent changes during the intervention period (Table 4). Hodgson et al. (2003) [58] hypothesized that high doses of tea solids (from black tea) may increase HCY due to possible acceptance of methyl groups by polyphenols during metabolism of methionine to homocysteine. But results showed that regular ingestion of black tea did not alter mean HCY concentrations in 21 subjects consuming $1250 \mathrm{~mL}$ black tea/d (5 cups each containing $2 \mathrm{~g}$ tea leaves in $250 \mathrm{~mL}$ boiled water).

Folate is a co-factor in the metabolism of homocysteine to methionine. Low folate level causes a rise in the homocysteine levels (called hyperhomocysteinemia) and is therefore considered angiogenic. Olthof et al. (2001) [59] reported that chlorogenic acid, a compound found in black tea and coffee, may cause a rise in total homocysteine concentrations by $12 \%(1.2 \mu \mathrm{mol} / \mathrm{L})$ in postprandial plasma and by $4 \%(0.4 \mu \mathrm{mol} / \mathrm{L})$ in fasting plasma. It also lowered the plasma fasting folate concentrations by $8 \%$. This observation is supported by the result of the present study where a consistent rise in HCY level has been noted in the females consuming tea (Table 4).

Long term supplementation may show a positive impact on CRP and HCY, which is not conclusive by 4 months.

\section{Conclusions}

Green tea exerts strong anti-oxidative effects and can have beneficial impact on health. The presence of metabolic syndrome acts as a prelude to impending risk of CVD which is known to be the leading cause of morbidity and mortality. The present study shows that consumption of green tea on regular basis may have positive effect on some of the important metabolic risk factors such as visceral fat, lipid profile (total and LDL cholesterol) and blood sugars (fasting blood sugar, HbA1C) within a short time (Table 5). However, inflammatory markers such as Hcy and CRP may require longer intervention period and higher doses to show observable trends with green tea supplementation. 
Table 5. Summary of experimental result of 4 months green tea consumption.

\begin{tabular}{|c|c|c|c|}
\hline Health Parameter & Biomarkers & 4 month period & SL \\
\hline \multirow[t]{3}{*}{ Body comp } & Weight & $\downarrow$ & $*$ \\
\hline & Waist circumference & $\downarrow$ & ** \\
\hline & BMI & $\leftrightarrow$ & NS \\
\hline \multirow[t]{3}{*}{ Blood Sugar } & FBS & $\downarrow$ & ** \\
\hline & HbA1C & $\downarrow$ & $* *$ \\
\hline & Fasting Insulin & $\leftrightarrow$ & NS \\
\hline \multirow[t]{5}{*}{ Lipid profile } & Total Cholesterol & $\downarrow$ & $* *$ \\
\hline & LDL-Cholesterol & $\downarrow$ & $* *$ \\
\hline & HDL-Cholesterol & $\downarrow$ & NS \\
\hline & TG & 4 & NS \\
\hline & VLDL & 4 & NS \\
\hline \multirow[t]{2}{*}{ Inflammatory Indicator } & CRP & 4 & $*$ \\
\hline & $\mathrm{HCY}$ & 4 & NS \\
\hline
\end{tabular}

The present study was conducted among free living population with regular monitoring and follow-up to ensure compliance and restrict lifestyle and other dietary changes. Therefore, the sample size (number of observation) was kept under control. More studies in the future using larger sample size and longer intervention period would help to substantiate the claims of beneficial effects of green tea consumption on CVD risk factors in individuals with metabolic syndrome.

\section{Acknowledgements}

We thank the local blood collection centre of Desai lab and the central analysis lab of Thyrocare for their role in successful double blind study. We are grateful to Institute for Lebensmittelchemie der Technischen Universitat Carolowilhelmina, Germany for analyzing the composition of green tea brew.

\section{Authors Disclosure Statement/Conflicts of Interest}

The project was conceptualized, undertaken, analyzed and written by the communicating author, sponsored by Tata Global Beverage Ltd, Bangalore, India. The report is unbiased and without conflicts of interest.

\section{References}

[1] Bhardwaj, P. and Khanna, D. (2013) Green Tea Catechins: Defensive Role in Cardiovascular Disorders. Chinese Journal of Natural Medicines, 11, 345-353.

[2] Babu, P.V. and Liu, D. (2008) Green Tea Catechins and Cardiovascular Health: An Update. Current Medicinal Chemistry, 15, 1840-1850. http://dx.doi.org/10.2174/092986708785132979

[3] Rains, T.M., Agarwal, S. and Maki, K.C. (2011) Antiobesity Effects of Green Tea Catechins: A Mechanistic Review. Journal of Nutritional Biochemistry, 22, 1-7. http://dx.doi.org/10.1016/j.jnutbio.2010.06.006

[4] Chen, T.S., Lui, C.K.F. and Smith, C.H. (1983) Folacin Content of Tea. Journal of the American Dietetic Association, 82, 627-632.

[5] Riddell, L.J., Chisholm, A., Williams, S., et al. (2000) Dietary Strategies for Lowering Homocysteine Concentrations. The American Journal of Clinical Nutrition, 71, 1448-1454.

[6] Hodgson, J., Devine, A., Puddey, I.B., et al. (2006) Drinking Tea Is Associated with Lower Plasma Total Homocysteine in Older Women. Asia Pacific Journal of Clinical Nutrition, 15, 253-258 
[7] Alberti, K.G.M.M., Zimmet, P. and Shaw, J. (2006) Metabolic Syndrome-A New World-Wide Definition. A Consensus Statement from the International Diabetes Federation. Diabetic Medicine, 23, 469-480. http://dx.doi.org/10.1111/j.1464-5491.2006.01858.x

[8] Ikeda, I. (2008) Multifunctional Effects of Green Tea Catechins on Prevention of the Metabolic Syndrome. Asia Pacific Journal of Clinical Nutrition, 17, 273-274.

[9] Zhen, X.-X., Xu, Y.-L., Li, S.-H., et al. (2011) Green Tea Intake Lowers Fasting Serum Total and LDL Cholesterol in Adults: A Meta-Analysis of 14 Randomized Controlled Trials. The American Journal of Clinical Nutrition, 94, 601610. http://dx.doi.org/10.3945/ajcn.110.010926

[10] Heng, D., Ma, S., Lee, J.J.M., et al. (2006) Modification of the NCEP ATP III Definitions of the Metabolic Syndrome for Use in Asians Identifies Individuals at Risk of Ischemic Heart Disease. Atherosclerosis, 186, 367-373. http://dx.doi.org/10.1016/j.atherosclerosis.2005.07.020

[11] Zaveri, N.T. (2006) Green Tea and Its Polyphenolic Catechins: Medicinal Uses in Cancer and Noncancer Applications. Life Sciences, 78, 2073-2080. http://dx.doi.org/10.1016/j.lfs.2005.12.006

[12] Trinder, P. (1969) Determination of Glucose in Blood Using Glucose Oxidase with an Alternative Oxygen Acceptor. Annals of Clinical Biochemistry, 6, 24-27. http://dx.doi.org/10.1177/000456326900600108

[13] Feldman, J.M. and Chapman, B.A. (1973) Radioimmunoassay of Insulin in Serum and Plasma. Clinical Chemistry, 19, 1250-1254.

[14] Nayak, S.S. and Pattabiraman, T.N. (1981) A New Colorimetric Method for the Estimation of Glycosylated Hemoglobin. Clinica Chimica Acta, 109, 267-274. http://dx.doi.org/10.1016/0009-8981(81)90312-0

[15] Schettler, G. and Nüssel, E.(1975) Arbeitsmed. Sozialmed. Präventivmed., 10, 25.

[16] Richmond, W. (1973) Preparation and Properties of a Cholesterol Oxidase from Nocardia sp. and Its Application to the Enzymatic Assay of Total Cholesterol in Serum. Clinical Chemistry, 19, 1350-1356.

[17] Roeschlau, P. (1974) Enzymatische bestimmung das Gesamt-choiesterins in serum. Zeitschrift für Klinische Chemie und Klinische Biochemie, 12, 403-407.

[18] Mayne, P.D. (1994) Clinical Chemistry in Diagnosis and Treatment. Vol. 11, 224.

[19] Jacobe, N.J. and Van Demark, P.J. (1960) The Purification and Properties of the $\alpha$-Glycerophosphate-Oxidizing Enzyme of Streptococcus faecalis 10C1. Archives of Biochemistry and Biophysics, 88, 250-255. http://dx.doi.org/10.1016/0003-9861(60)90230-7

[20] Werner, M., Gabrielson, D.G. and Eastman, J. (1981) Ultramicro Determination of Serum Triglycerides by Bioluminescent Assay. Clinical Chemistry, 27, 268-271.

[21] Koditschek, L.K. and Umbreit, W.W. (1969) Alpha-Glycerophosphate Oxidase in Streptococcus faecium F 24. Journal of Bacteriology, 98, 1063-1068.

[22] Castelli, W.P., Doyle, J.T., Gordon, T., Hames, C.G., Hjortland, M.C., Hulley, S.B., Kagan, A. and Zukel, W.J. (1977) HDL Cholesterol and Other Lipids in Coronary Heart Disease: Cooperative Lipoprotein Phenotyping Study. Circulation, 55, 767-772. http://dx.doi.org/10.1161/01.CIR.55.5.767

[23] Burstein, M., Scholnic, H.R. and Morfin, R. (1970) Rapid Method for the Isolation of Lipoproteins from Human Serum by Precipitation with Polyanion. Journal of Lipid Research, 11, 583-595.

[24] Young, D.S. (1990) Effects of Drugs on Clinical Laboratory Tests. Vol. 3, 3rd Edition, AACC Press, Washington DC, 104-106.

[25] Tietz, N.W. (1986) Textbook of Clinical Chemistry. W.B. Saunders, Philadelphia, 874-881.

[26] Hohenwallner, W., Sommer, R., Wimmer, E. and Tschurtschenthaler, G.V. (1980) Quality Control in Assay of HighDensity Lipoprotein Cholesterol. Clinical Chemistry, 26, 177-178.

[27] Tietz, N.W., Finley, P.R. and Pruden, E.L. (1990) Clinical Guide to Laboratory Tests. 2nd Edition, W.B. Saunders, Philadelphia, 304-306.

[28] Friedewald, W.T., Levy, R.I. and Fredrickson, D.S. (1972) Estimation of the Concentration of Low-Density Lipoprotein Cholesterol in Plasma, without Use of the Preparative Ultracentrifuge. Clinical Chemistry, 18, 499-502.

[29] Hansson, L.O. and Lindquist, L. (1997) C-Reactive Protein: Its Role in the Diagnosis and Follow-Up of Infectious Diseases. Current Opinion in Infectious Diseases, 10, 196-201. http://dx.doi.org/10.1097/00001432-199706000-00007

[30] Vaishnavi, C. (1996) Immunology and Infectious Diseases, 6, 139-144.

[31] Pulki, K., et al. (1986) Scandinavian Journal of Clinical \& Laboratory Investigation, 46, 606-607.

[32] Hokama, Y. and Nakamura, R.M. (1987) C-Reactive Protein: Current Status and Future Perspectives. Journal of Clinical Laboratory Analysis, 1, 15-27. http://dx.doi.org/10.1002/jcla.1860010104 
[33] Müller, W., Mierau, R. and Wohltmann, D. (1985) Interference of IgM Rheumatoid Factor with Nephelometric C-Reactive Protein Determinations. Journal of Immunological Methods, 80, 77-90. http://dx.doi.org/10.1016/0022-1759(85)90166-8

[34] Otsuji, S., Shibata, H. and Umeda, M. (1982) Turbidimetric Immunoassay of Serum C-Reactive Protein. Clinical Chemistry, 28, 2121-2124.

[35] Tan, Y.Y., Sun, X., Tang, L., Zhang, N., Han, Q.H., Xu, M.X., Tan, X.Z., Tan, X.Y. and Hoffman, R.M. (2003) Automated Enzymatic Assay for Homocysteine. Clinical Chemistry, 49, 1029-1030. http://dx.doi.org/10.1373/49.6.1029

[36] Wolfram, S., Wang, Y. and Thielecke, F. (2006) Anti-Obesity Effects of Green Tea: From Bedside to Bench. Molecular Nutrition \& Food Research, 50, 176-187. http://dx.doi.org/10.1002/mnfr.200500102

[37] Dulloo, A.G., Duret, C., Rohrer, D., Girardier, L., Mensi, N., Fathi, M., Chantre, P. and Vandermander, J. (1999) Efficacy of a Green Tea Extract Rich in Catechin Polyphenols and Caffeine in Increasing 24-h Energy Expenditure and Fat Oxidation in Humans. American Journal of Clinical Nutrition, 70, 1040-1045.

[38] WHO. World Health Organization Fact Sheet for World Wide Prevalence of Obesity. http://www.who.int/mediacentre/factsheets/fs311/en/

[39] Fernández-Sánchez, A., Madrigal-Santillán, E., Bautista, M., Esquivel-Soto, J., Morales-González, Á., Esquivel-Chirino, C., et al. (2011) Inflammation, Oxidative Stress, and Obesity. International Journal of Molecular Sciences, 12, 3117 3132. http://dx.doi.org/10.3390/ijms12053117

[40] Senger, A.E.V., Schwanke, C.H., Gomes, I. and Valle Gottlieb, M.G. (2012) Effect of Green Tea (Camellia sinensis) Consumption on the Components of Metabolic Syndrome in Elderly. Journal of Nutrition, Health \& Aging, 16, 738742. http://dx.doi.org/10.1007/s12603-012-0081-5

[41] Etchison, W.C., Bloodgood, E.A., Minton, C.P., Thompson, N.J., Collins, M.A., Hunter, S.C. and Dai, H. (2011) Body Mass Index and Percentage of Body Fat as Indicators for Obesity in an Adolescent Athletic Population. Sports Health, 3, 249-252. http://dx.doi.org/10.1177/1941738111404655

[42] Ode, J., Pivarnik, J.M., Reeves, M.J. and Knous, J.L. (2007) Body Mass Index as a Predictor of Percent Fat in College Athletes and Nonathletes. Medicine \& Science in Sports \& Exercise, 39, 403-409. http://dx.doi.org/10.1249/01.mss.0000247008.19127.3e

[43] Maruyama, K., Iso, H., Sasaki, S. and Fukino, Y. (2009) The Association between Concentrations of Green Tea and Blood Glucose Levels. Journal of Clinical Biochemistry and Nutrition, 44, 41-45. http://dx.doi.org/10.3164/jcbn.08-13

[44] Veeranna, V., Ramesh, K., Zalawadiya, S.K., Niraj, A., Pradhan, J., Jacob, S. and Afonso, L. (2011) Glycosylated Hemoglobin and Prevalent Metabolic Syndrome in Nondiabetic Multiethnic U.S. Adults. Metabolic Syndrome and Related Disorders, 9, 361-367. http://dx.doi.org/10.1089/met.2011.0032

[45] Eeg-Olofsson, K., Cederholm, J., Nilsson, P.M., Zethelius, B., Svensson, A.M., Gudbjörnsdóttir, S. and Eliasson, B. (2012) New Aspects of HbA1c as a Risk Factor for Cardiovascular Diseases in Type 2 Diabetes: An Observational Study from the Swedish National Diabetes Register (NDR). Journal of Internal Medicine, 268, 471-482. http://dx.doi.org/10.1111/j.1365-2796.2010.02265.x

[46] Liu, K., Zhou, R., Wang, B., Chen, K., Shi, L.Y., Zhu, J.D. and Mi, M.T. (2013) Effect of Green Tea on Glucose Control and Insulin Sensitivity: A Meta-Analysis of 17 Randomized Controlled Trials. American Journal of Clinical Nutrition, 98, 340-348. http://dx.doi.org/10.3945/ajcn.112.052746

[47] Singhania, P., Gupta, G. and Sen Ray, K. (2013) Inflammatory Biomarkers in Asian Indian Women with Metabolic Syndrome. Food \& Nutrition Sciences, 4, 1021-1027. http://dx.doi.org/10.4236/fns.2013.410133

[48] Bryans, J.A., Judd, P.A. and Ellis, P.R. (2007) The Effect of Consuming Instant Black Tea on Postprandial Plasma Glucose and Insulin Concentrations in Healthy Humans. Journal of the American College of Nutrition, 26, 471-477. http://dx.doi.org/10.1080/07315724.2007.10719638

[49] Jellinger, P.S., Smith, D.A., Mehta, A.E., Ganda, O., Handelsman, Y., Rodbard, H.W., Shepherd, M.D. and Seibel, J.A., The AACE Task Force for Management of Dyslipidemia and Prevention of Atherosclerosis (2012) American Association of Clinical Endocrinologists' Guidelines for Management of Dyslipidemia and Prevention of Atherosclerosis. Endocrine Practice, 18, 1-78.

[50] University of Maryland Medical Center. Green Tea. http://umm.edu/health/medical/altmed/herb/green-tea\#ixzz2tJIIrUsH

[51] Chan, P.T., Fong, W.P., Cheung, Y.L., Huang, Y., Ho, W.K. and Chen, Z.Y. (1999) Jasmine Green Tea Epicatechins Are Hypolipidemic in Hamsters (Mesocricetus auratus) Fed a High Fat Diet. Journal of Nutrition, 129, $1094-1101$.

[52] Saleem, M., Rani, S. and Gautham, K. (2011) High-Density Lipoproteins: A Novel Therapeutic Target for Cardiovascular Disease. Research Reports in Clinical Cardiology, 2, 1-6. http://dx.doi.org/10.2147/RRCC.S15600

[53] Tokunaga, S., White, I.R., Frost, C., Tanaka, K., Kono, S., Tokudome, S., et al. (2002) Green Tea Consumption and Serum Lipids and Lipoproteins in a Population of Healthy Workers in Japan. Annals of Epidemiology, 12, 157-165. 
http://dx.doi.org/10.1016/S1047-2797(01)00307-6

[54] Juhel, C., Armand, M., Pafumi, Y., Rosier, C., Vandermander, J. and Lairon, D. (2000) Green Tea Extract (AR25) Inhibits Lipolysis of Triglycerides in Gastric and Duodenal Medium in Vitro. Journal of Nutritional Biochemistry, 11, 45-51. http://dx.doi.org/10.1016/S0955-2863(99)00070-4

[55] Danesh, J., Whincup, P., Walker, M., Lennon, L., Thomson, A., Appleby, P., et al. (2000) Low Grade Inflammation and Coronary Heart Disease: Prospective Study and Updated Meta-Analysis. British Medical Journal, 321, 199-204. http://dx.doi.org/10.1136/bmj.321.7255.199

[56] Ridker, P.M. and Cook, N. (2004) Clinical Usefulness of Very High and Very Low Levels of C-Reactive Protein across the Full Range of Framingham Risk Scores. Circulation, 109, 1955-1959. http://dx.doi.org/10.1161/01.CIR.0000125690.80303.A8

[57] Maki, T., Pham, N.M., Yoshida, D., Yin, G., Ohnaka, K., Takayanagi, R. and Kono, S. (2010) The Relationship of Coffee and Green Tea Consumption with High-Sensitivity C-Reactive Protein in Japanese Men and Women. Clinical Chemistry and Laboratory Medicine, 48, 849-854. http://dx.doi.org/10.1515/CCLM.2010.161

[58] Hodgson, J.M., Burke, V., Beilin, L.J., Croft, K.D. and Puddey, I.B. (2003) Can Black Tea Influence Plasma Total Homocysteine Concentrations? American Journal of Clinical Nutrition, 77, 907-911.

[59] Olthof, M.R., Hollman, P.C., Zock, P.L. and Katan, M.B. (2001) Consumption of High Doses of Chlorogenic Acid, Present in Coffee, or of Black Tea Increases Plasma Total Homocysteine Concentrations in Humans. American Journal of Clinical Nutrition, 73, 532-538. 
Scientific Research Publishing (SCIRP) is one of the largest Open Access journal publishers. It is currently publishing more than 200 open access, online, peer-reviewed journals covering a wide range of academic disciplines. SCIRP serves the worldwide academic communities and contributes to the progress and application of science with its publication.

Other selected journals from SCIRP are listed as below. Submit your manuscript to us via either submit@scirp.org or Online Submission Portal.
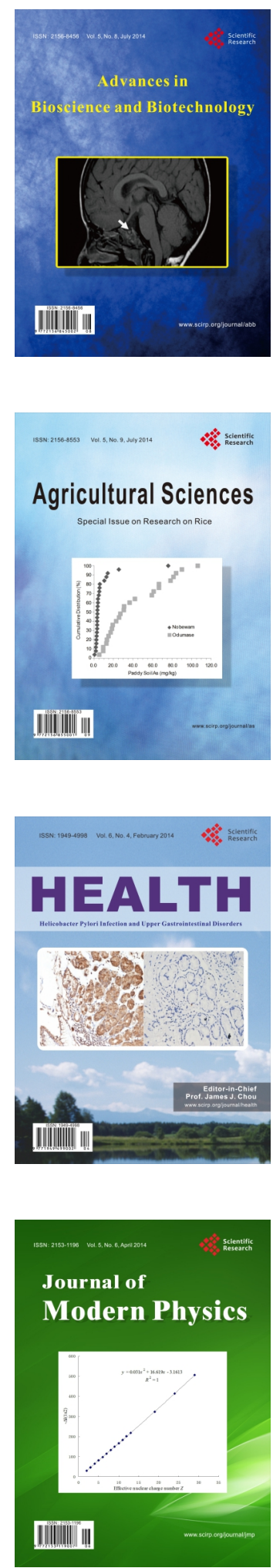
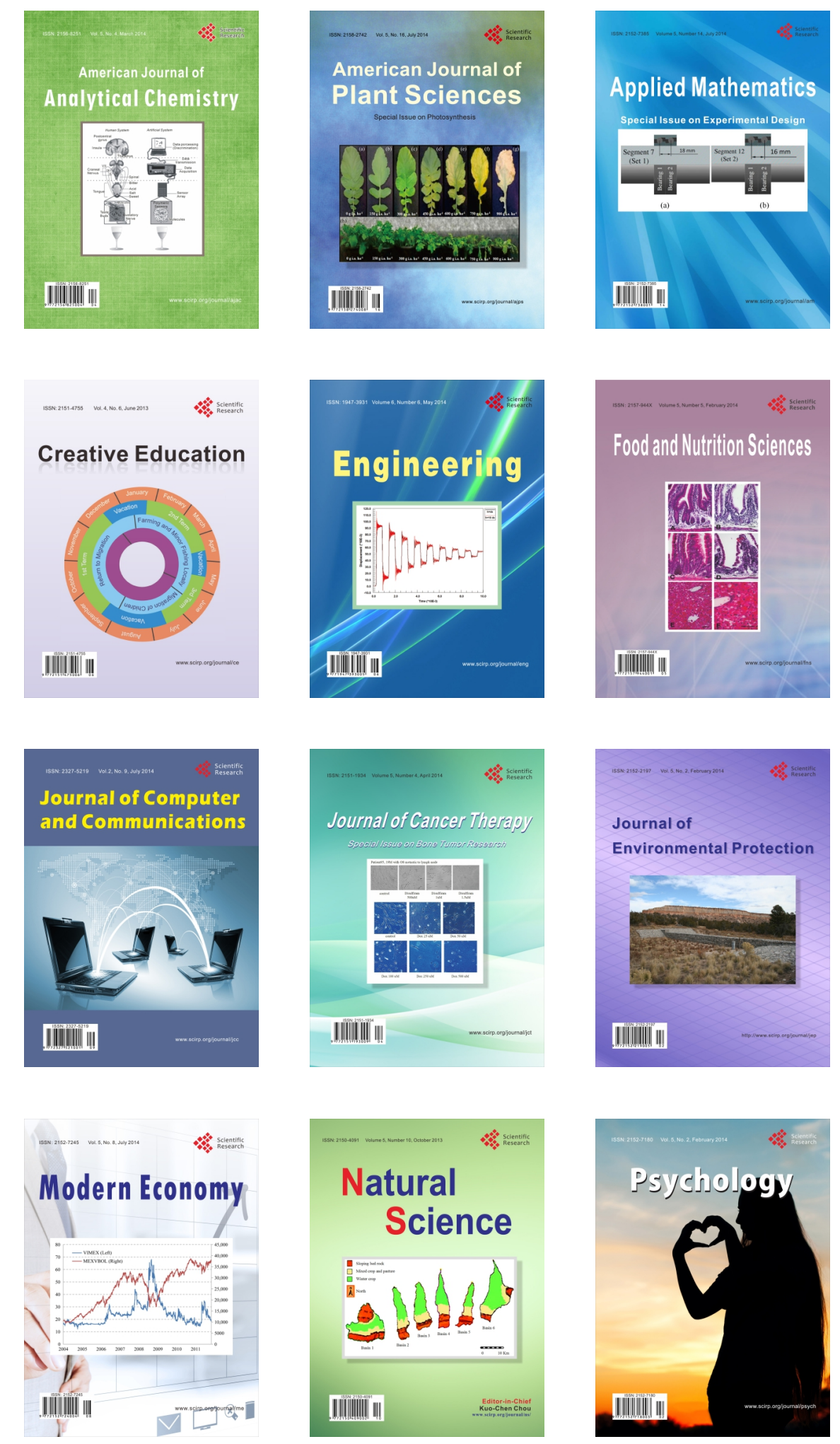